ISSN 0103-9954

\title{
OCORRÊNCIA DE INCÊNDIOS FLORESTAIS NO PARQUE NACIONAL DA CHAPADA DOS VEADEIROS, GOIÁS
}

\author{
FIRES INCIDENT OCCURRENCE IN PARQUE NACIONAL DA CHAPADA DOS VEADEIROS, \\ GOIÁS
}

\author{
Nilton César Fiedler ${ }^{1}$ Daniela Araújo Merlo ${ }^{2}$ Marcelo Brilhante de Medeiros ${ }^{3}$
}

\section{RESUMO}

Esta pesquisa objetivou a análise da ocorrência de incêndios florestais no Parque Nacional da Chapada dos Veadeiros (PNCV), GO, no período de 1992 a 2003. A metodologia utilizou mapas de focos de calor, dados dos relatórios de ocorrência de incêndios na Unidade de Conservação, entrevistas aos brigadistas e à comunidade do entorno. Com esses dados, foi possível analisar as causas e a freqüência de ocorrência de incêndios florestais, as áreas queimadas anualmente, os locais e épocas de incidência, o trabalho de prevenção e combate desenvolvido pelos brigadistas e a opinião da população em relação ao trabalho desenvolvido no Parque. Essas informações possibilitaram analisar as ocorrências de fogo no PNCV e alguns dados importantes sobre prevenção e combate aos incêndios. Os incêndios florestais no PNCV ocorreram praticamente em todos os anos, sendo que 1995 e 2002 foram os anos mais críticos. 88,2\% dos incêndios florestais foram de origem criminosa, por negligência ou de causa desconhecida. A época em que mais ocorreram os incêndios foi a estação seca, sendo o pico o mês de agosto, seguido pelos meses de setembro e julho. As ações preventivas realizadas no PNCV são a construção de aceiros e a distribuição de cartazes educativos. A comunidade local salientou que falta estímulo à utilização de técnicas de substituição ao uso do fogo nas propriedades rurais e campanhas educativas de prevenção de incêndios florestais.

Palavras-chave: padrões de uso do fogo; unidades de conservação; histórico de fogo.

\section{ABSTRACT}

This work aimed at studying the fires in Parque Nacional da Chapada dos Veadeiros (PNCV) in Goiás, Brazil, from 1992 to 2003. The methodology included analysis of heat spots maps, reports and interviews with the fire crew members, besides interviews with the land owners who live close to the PNCV. The data showed the causes and the frequencies of fires annual burnt areas, seasons and origins of fire incident, and fire privation developed by the fire crew of PNCV. Furthermore, there was opinions by land owner related to the PNCV. Results showed that the fires in PNCV had annual frequency. The years 1995 and 2002 presented more fire occurrences. Most of the fires $(88,2 \%)$ had criminal or unknown causes. The dry season caused more fire occurrences, mainly August, September and July. The prevention activities were break fires construction and instruction folders related to fires release. The local land owners did not know how to deal with land management techniques without fire and asked for environmental education.

Keywords: wildfires patterns; conservation units; fire historic.

\section{INTRODUÇÃO}

A ocupação desordenada da área central do País, para expandir a produção agrícola e pecuária, tem sido considerada a principal causa de degradação do Cerrado. Essa modificação na paisagem do Brasil Central tem, entre outros efeitos, causado um aumento na frequência de fogo na região e, provavelmente, alterado a capacidade de recuperação de elementos da biota mais sensíveis a esse distúrbio.

Com o intuito de preservar os ambientes físicos, bióticos e culturais têm sido implantadas algumas Unidades de Conservação, na tentativa de diminuir a pressão antrópica sobre remanescentes dos grandes biomas brasileiros. O Parque Nacional da Chapada dos Veadeiros (PNCV) insere-se nesse contexto como uma importante área de conservação do Bioma Cerrado. A região da Chapada dos Veadeiros, no nordeste do estado de Goiás, tem sido atingida por incêndios florestais de grandes dimensões.

1. Eng. Florestal, Dr., Professor Adjunto do Departamento de Engenharia Florestal, Centro de Ciências Agrárias, Universidade Federal do Espírito Santo, Alto Universitário s/n, CEP 29.500-000, Alegre (ES). fiedler@cca.ufes.br

2. Engenheira Florestal, Departamento de Engenharia Florestal, Universidade de Brasília, Caixa Postal 04357, CEP 70.910-900, Brasília (DF).

3. Biólogo, Dr., Pesquisador da EMBRAPA/CENARGEN, Parque Estação Biológica, Av. W5 Norte, Final, Caixa Postal, 1 02372, CEP 70.770-900, Brasília (DF).medeiros@cenargen.embrapa.br

Recebido para publicação em 26/04/2005 e aceito em 6/06/2006. 
O planejamento de prevenção e combate aos incêndios florestais em uma Unidade de Conservação depende do levantamento das causas, da freqüência e das conseqüências do fogo em uma determinada área, entre outros conhecimentos. Assim, um dos principais fundamentos para proteger as Unidades de Conservação é a pesquisa sobre os padrões históricos de incêndios florestais no seu interior e entorno (Matos, 2004).

As áreas de Cerrado são caracterizadas por uma estação seca definida onde a vegetação local é mais propensa ao fogo, com predominância de formações abertas de cerrado, é muito comum a ocorrência de incêndios de causas antrópicas e naturais (Ramos-Neto, 2000). Os incêndios de causa antrópica são ocasionados, sobretudo, por queimadas feitas sem controle para renovação de pastagens nas fazendas da região, como tem sido observado em outras Unidades de Conservação do Cerrado (Medeiros, 2002).

Este trabalho teve como objetivo principal a análise da ocorrência de incêndios florestais no PNCV, no período de 1992 a 2003, baseando-se na descrição e análise das causas, freqüência, área queimada e época do ano; na análise das ações de prevenção e a percepção das comunidades do entorno em relação ao problema dos incêndios florestais.

\section{MATERIAL E MÉTODOS}

\section{Área de Estudo}

O PNCV insere-se na categoria de Parques Nacionais que foram criados com base no Código Florestal, Lei n. 4.771, de 15 de setembro de 1965, e na Lei de n. 5.197 (Proteção à Fauna), de 3 de janeiro de 1967, e foram definidos como unidades de uso indireto pelo Decreto 84.017, de 21 de setembro de 1979, (Regulamento dos Parques Nacionais Brasileiros). Assim são considerados enquanto áreas geográficas extensas e delimitadas, dotadas de atributos excepcionais para garantir a proteção integral da flora e fauna silvestre, dos solos, das águas e das belezas cênicas, com objetivos científicos, educacionais, recreativos e culturais (PREVFOGO, 2004).

O PNCV possui uma área de 65.514,73 ha e está localizado no nordeste do estado de Goiás, entre os municípios de Alto Paraíso de Goiás, Cavalcante e Colinas do Sul. É delimitado pelas coordenadas de $13^{\circ} 51^{\text {' }}$ a $14^{\circ} 10^{\prime}$ de latitude sul e $47^{\circ} 25^{\prime}$ a $47^{\circ} 42^{\prime}$ de longitude oeste (Vicentini, 1999). A unidade fica a $260 \mathrm{~km}$ de Brasília DF e a $480 \mathrm{~km}$ de Goiânia, GO (Figura 1). O PNCV é considerado a maior área de conservação ambiental e o mais importante atrativo ecoturístico da região.

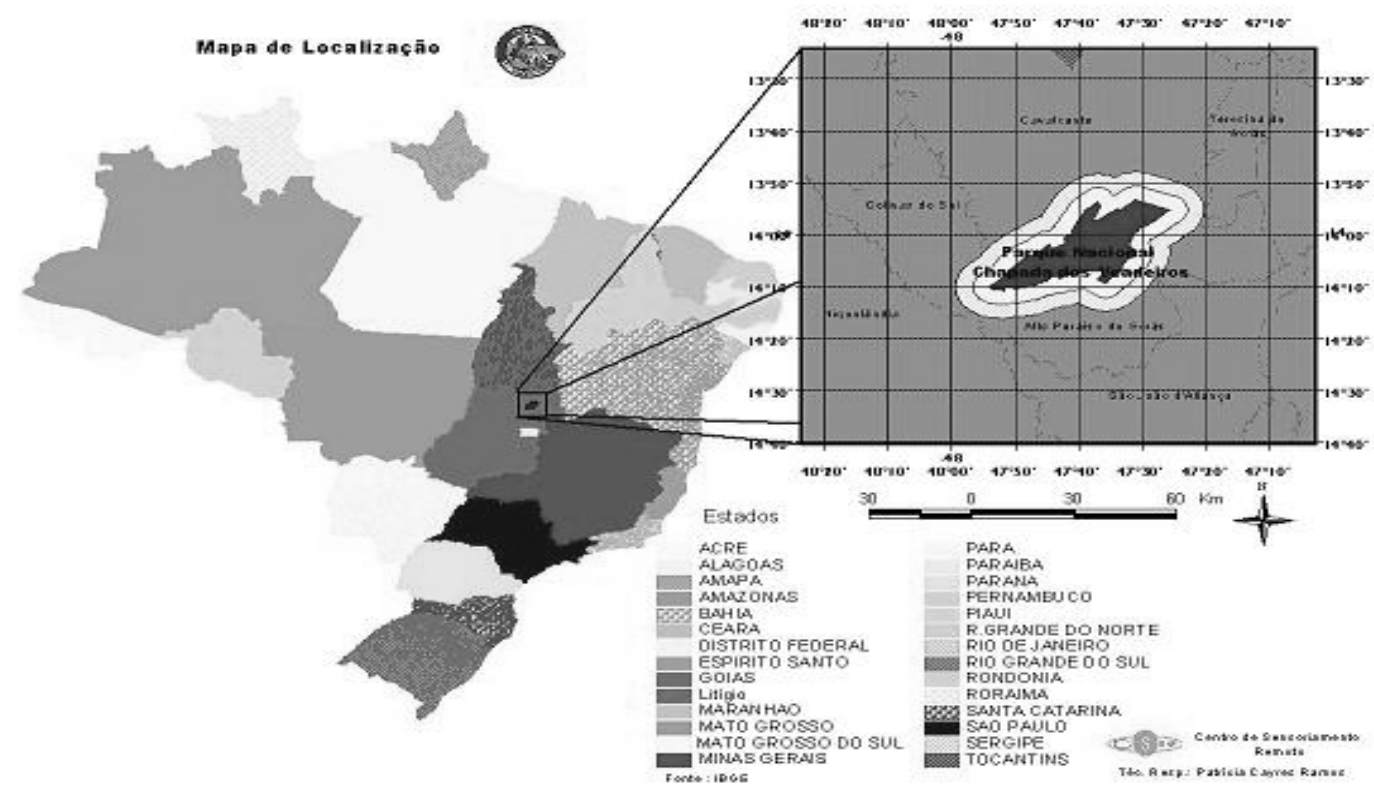

FIGURA 1: Localização do Parque Nacional da Chapada dos Veadeiros, GO.

FIGURE 1: Parque Nacional da Chapada dos Veadeiros, GO, localization. 
Para maior facilidade na análise dos dados e discussão dos resultados, utilizou-se a divisão das áreas do PNCV proposta pelo Plano de Manejo de Fogo da Unidade de Conservação (PREVFOGO, 2004). Essa divisão foi feita com apoio e participação de funcionários do Parque, baseando-se no conhecimento local sobre os nomes e limites das zonas em quatorze microrregiões. Quanto aos limites das zonas, foram considerados parâmetros geográficos, tais como rios, vales, serras e os limites do próprio Parque (Figura 7). Essa divisão visa a auxiliar na definição de estratégias para prevenção, monitoramento e combate ao fogo na Unidade.

\section{Coleta de Dados}

Os dados dessa pesquisa foram coletados por meio de um levantamento das ocorrências de incêndios florestais no PNCV. A metodologia usada foi a aplicação de questionários e a busca no acervo de documentos do PREVFOGO (Centro Nacional de Prevenção e Combate aos Incêndios Florestais), vinculado ao Instituto Brasileiro de Meio Ambiente e Recursos Naturais Renováveis-IBAMA, conforme descrito abaixo:

- Registros documentados no PREVFOGO/IBAMA (planos de manejo, mapas e relatórios de ocorrência de incêndios (ROI). O período de abrangência envolveu os anos de 1992 a 2003.

- Focos de calor imageados pelo satélite NOAA-12, sensor AVHRR, passagens noturnas das 18:00 às 19 h 45 min, horário de Brasília, no período de 1992 a 2003, captadas pelas antenas do INPE (Instituto Nacional de Pesquisas Espaciais) que cobrem praticamente todo o território brasileiro.

- Coleta de informações diretamente no local: foi aplicada uma entrevista semiestruturada individual aos sete brigadistas da Unidade de Conservação, nos meses de setembro e outubro de 2004. A entrevista versava sobre atividades de prevenção realizada no interior da Unidade de Conservação, métodos de detecção usados, tempo médio de detecção de focos, sistema de comunicação, formas de combate usuais e principais dificuldades encontradas no combate.

- Aplicação de uma entrevista semiestruturada aos moradores na região entre a Vila de São Jorge e a sede do município de Alto Paraíso (GO-118, rodovia que dá acesso ao PNCV). Os entrevistados foram escolhidos aleatoriamente dentro das características necessárias à pesquisa, ou seja, pessoas que residem na região, trabalham direta ou indiretamente relacionados com o PNCV, ou ainda, proprietários de áreas nas imediações. Foram entrevistadas 22 famílias durante os meses de setembro e outubro de 2004. A entrevista versava sobre tempo de residência na região, conhecimento sobre métodos de prevenção e combate aos incêndios florestais, orientações técnicas recebidas e sugestões para diminuição da incidência de incêndios florestais na região.

\section{RESULTADOS E DISCUSSÃO}

\section{Ocorrência de Incêndios}

Os dados dos Relatórios de Ocorrência de Incêndios Florestais (ROIs) mostraram o registro de sessenta ocorrências de incêndios florestais no interior da Unidade no período de 1992 a 2003. Os únicos anos sem registro de incêndios florestais foram 1996 e 1997. O ano de maior ocorrência de incêndios foi 2002, com 11 casos, seguido por 1995, com dez ocorrências. Imagens do satélite NOAA-12 revelaram 184 focos de calor no interior da Unidade no mesmo período.

A comparação entre os dados dos Relatórios de Ocorrências de Incêndios (ROI) e os focos de calor registrados pelo satélite NOAA 12, no mesmo período, é mostrada na Figura 2.

Uma análise da Figura 2 indica que a região tem ocorrência anual de incêndios florestais, tendo uma maior incidência de focos de calor em relação aos números de ocorrências de incêndios registradas. Os ROIs são feitos com base nos incêndios, ou seja, na realidade de campo, atingindo uma extensa área e contados uma única vez. Entretanto, para a estatística de focos de calor, são computados todos os pixels da imagem do NOOA 12. Com isso, um único incêndio pode ter muitos pixels, que são os focos de calor. Somente nos anos de 1994 e 2002, houve mais registros de ocorrência de incêndios que focos de calor. Ocorreram sete registros de incêndios e oito focos de calor em 1994 e dois registros de incêndios e onze focos de calor em 2002. 


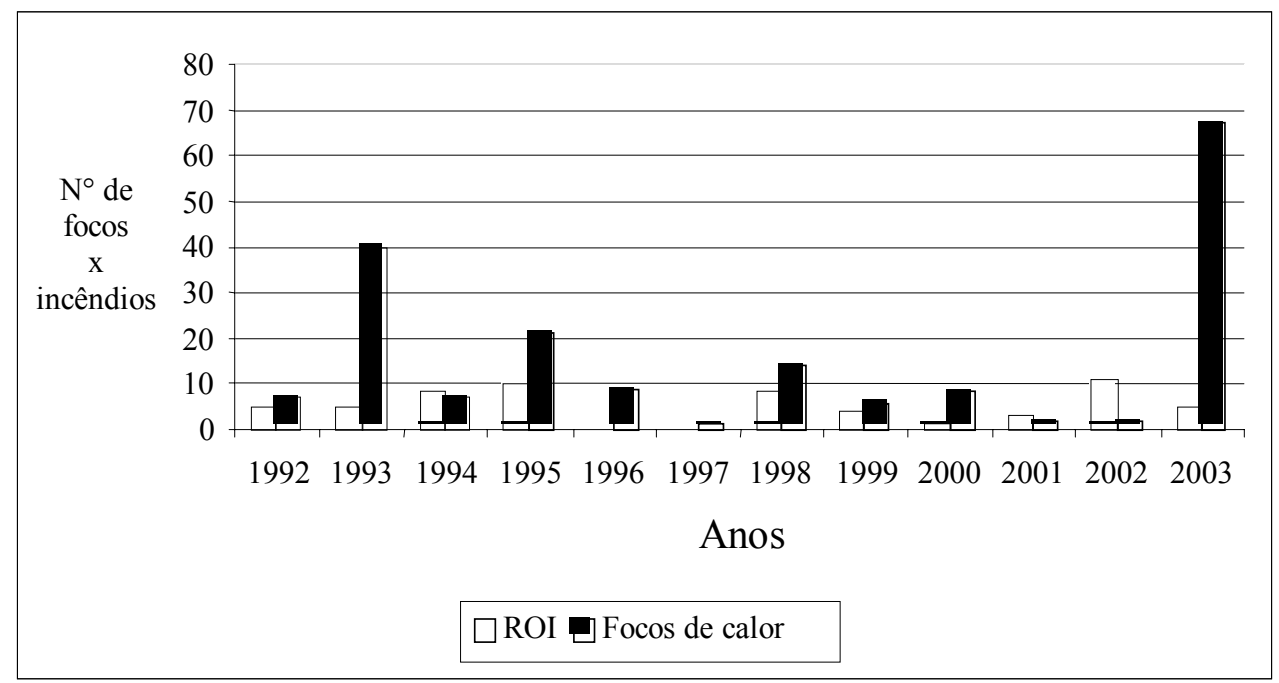

FIGURA 2: Comparação entre os registros de ocorrências de incêndios (ROI) e os focos de calor detectados pelo satélite NOAA 12 no período de 1992 a 2003.

FIGURE 2: Fires reports (ROI) and spot fires detected by NOAA 12 satellite from 1992 to 2003 in Parque Nacional da Chapada dos Veadeiros, GO.

\section{Causas dos incêndios florestais}

As causas foram analisadas de acordo com a classificação da FAO, descrita por Soares (1985).

Os incêndios ocorridos no PNCV foram de origem antrópica ou natural. Dentre os de causa antrópica, que somaram $88,24 \%$ do total de incêndios, ocorreram no PNCV os seguintes: criminosos, queima de pasto, garimpo, queima de beira de estrada, acidente (incluindo os aceiros), incendiários e de causa antrópica desconhecida. Os incêndios de causa natural por raios somaram $11,76 \%$ do total de incêndios.

A causa principal dos incêndios tem sido as queimadas de origem desconhecida e criminosa (Figura 3). Em menor escala, ocorreram incêndios provocados por renovação de pastagem e raios (descargas elétricas). Os incêndios ocasionados por raios atingem, em geral, áreas menores, por ocorrerem quase sempre na estação úmida e serem muitas vezes extintos pelas chuvas subseqüentes, sendo um padrão comum em Unidades de Conservação do Cerrado (Ramos-Neto, 2000; Medeiros, 2002; Medeiros e Fiedler, 2004).

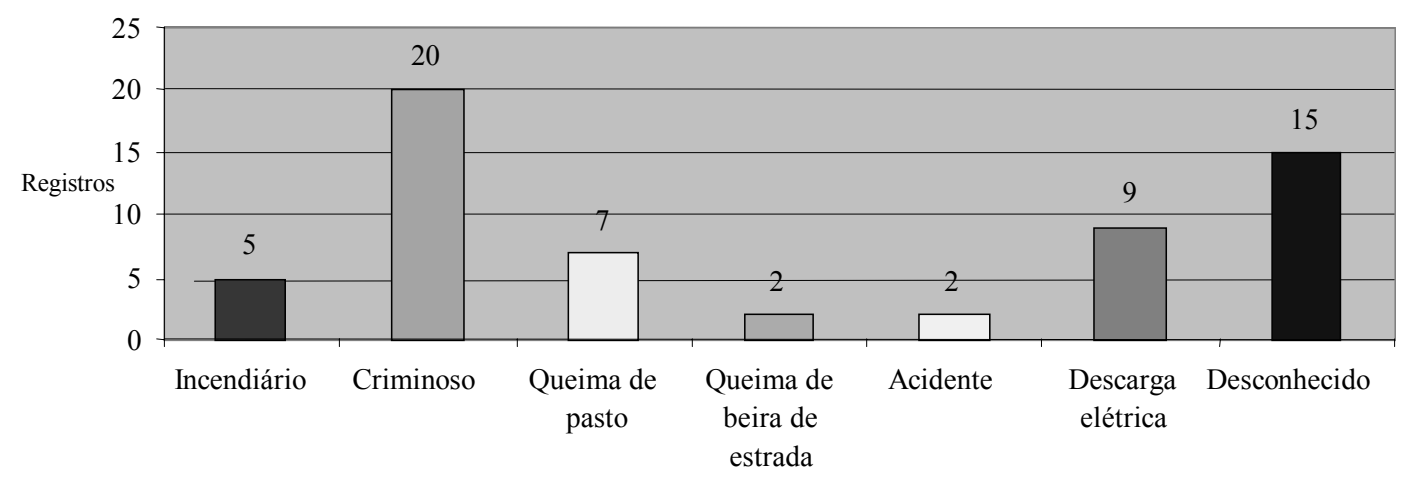

Causas

FIGURA 3: Causas de incêndios no período de 1992 a 2003 no PNCV.

FIGURE 3: Causes of fires from 1992 to 2003 in Parque Nacional da Chapada dos Veadeiros, GO.

É importante observar que as ocorrências de causa desconhecida, que foram consideradas como de origem antrópica, somam aproximadamente $34 \%$ dos eventos. Isso pode ser conseqüência da precariedade do sistema de detecção e perícias, muitas vezes, não sendo possível a determinação da causa desses incêndios. A quantidade dos incêndios ocasionados por queima de pastagem pode ser ainda maior, pois a região tem 
muitas fazendas que usam o fogo como instrumento de manejo de pastagem, sem o cuidado necessário. Esse tipo de causa tem sido a mais importante em várias regiões do País, como na Amazônia (Nepstad et al., 1999) e Cerrado (Medeiros, 2002; Medeiros e Fiedler, 2004).

\section{Freqüência de ocorrência de incêndios florestais}

Segundo Silva (1999), o aumento da freqüência de queima foi um dos aspectos que sofreu maiores alterações após o início da utilização do fogo pelo homem. De acordo com os dados do ROI, a frequência de fogo no Parque Nacional da Chapada dos Veadeiros é anual (Figura 4), ou seja, elevada. A grande diferença observada entre os dados do ROI e do satélite mostra que parte dos incêndios ocorridos no interior da Unidade de Conservação pode não estar sendo registrada no ROI.

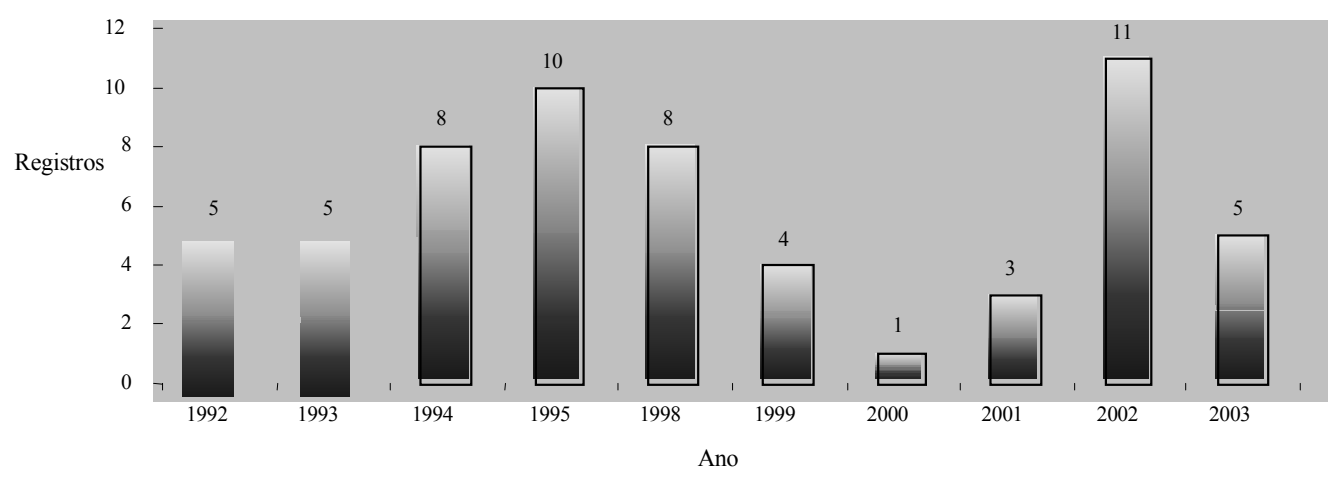

FIGURA 4: Freqüência anual de incêndios no período de 1992-2003 no PNCV.

FIGURE 4: Fires frequency from 1992 to 2003 in Parque Nacional da Chapada dos Veadeiros, GO.

Os anos com número maior de registro de incêndios florestais foram 2002 (11 ocorrências de incêndios), seguidos de 1995 (10 ocorrências) e 1994 e 1998 (8 ocorrências de incêndio cada um). No ano de 2000, foi registrada apenas uma ocorrência de incêndio florestal. Segundo os registros, nos anos de 1996 e 1997, não ocorreram incêndios.

\section{Análise das áreas queimadas}

Pelas características locais (área de entorno do PNCV com fazendas de criação extensiva de gado) e dados obtidos com a população da região, antes de 1990, os incêndios apresentavam padrão semelhante ao atual, com elevada freqüência e afetando áreas extensas (Figura 5). Esse padrão de áreas extensas afetadas por incêndios antrópicos também tem sido observado em outras Unidades de Conservação do Cerrado (Ramos-Neto, 2000; Medeiros, 2002; Medeiros e Fiedler, 2004).

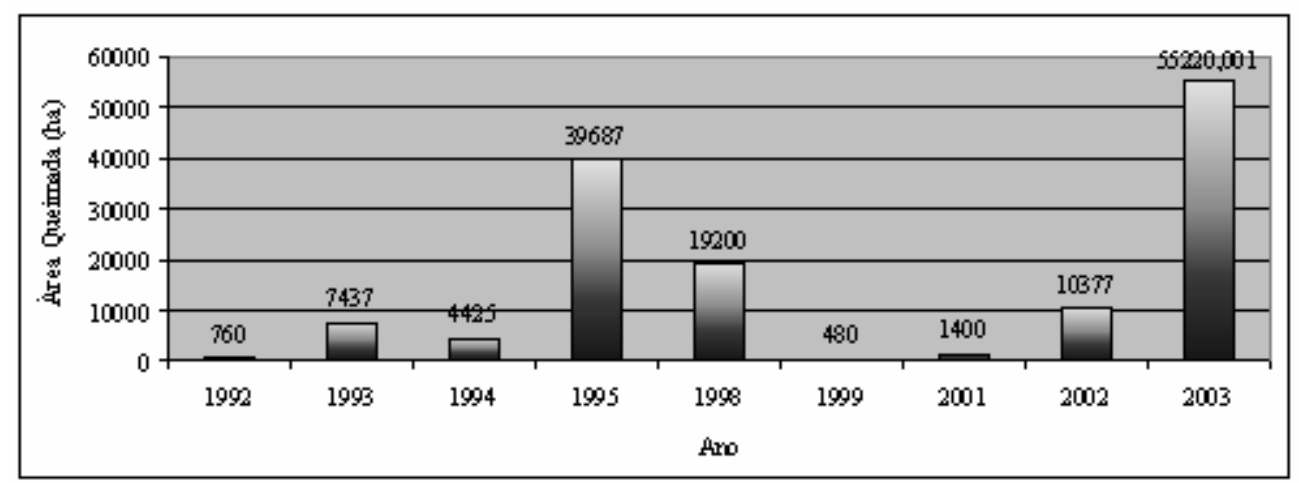

FIGURA 5: Áreas (ha) atingidas por incêndios florestais no período de 1992 a 2003 no PNCV.

FIGURE 5: Burnt areas from 1992 to 2003 in Parque Nacional da Chapada dos Veadeiros, GO.

No ano de 2000, não há dados de área queimada, apesar de haver uma ocorrência de incêndio. Os anos com maior área queimada foram 2003, quando houve um grande incêndio que atingiu aproximadamente $84 \%$ da área do parque e 1995 que queimou cerca de $60 \%$ do parque. 
Deve-se salientar que as informações sobre tamanho das áreas queimadas, obtidas nos Relatórios de Ocorrência de Incêndios Florestais - ROI, podem não ser precisas. Isso se deve ao fato das informações sobre áreas queimadas serem em alguns casos estimadas, pois, as vezes, não se utilizavam instrumentos e técnicas adequadas (GPS e imagens de satélites).

Observa-se, na Figura 5, que ocorreram incêndios de grandes proporções e com um número reduzido de ocorrências, como é o caso do ano de 2003. Já nos ano de 2002, apesar de haver um número maior de ocorrências, a área queimada foi bem menor.

A área queimada por raios pode estar subestimada, considerando a dificuldade de visualização, o relevo acidentado e a rápida extinção que esse tipo de incêndios geralmente apresenta. Os incêndios de causa natural, geralmente, atingem áreas pequenas por causa da chuva que normalmente vem posterior aos raios e, teoricamente, pode desempenhar um papel importante na manutenção da biodiversidade das formações vegetais mais abertas do Cerrado ao manter a heterogeneidade das comunidades de plantas do estrato herbáceo (Ramos-Neto, 2000; Medeiros e Fiedler, 2003). Porém, pesquisas devem ser feitas para monitoramento desse e de outros tipos de ocorrência de fogo para avaliação de impactos da biota local (Medeiros, 2002).

\section{Locais de maior ocorrência de incêndios}

A Figura 6 mostra os locais no interior do PNCV com maiores ocorrências de incêndios florestais.

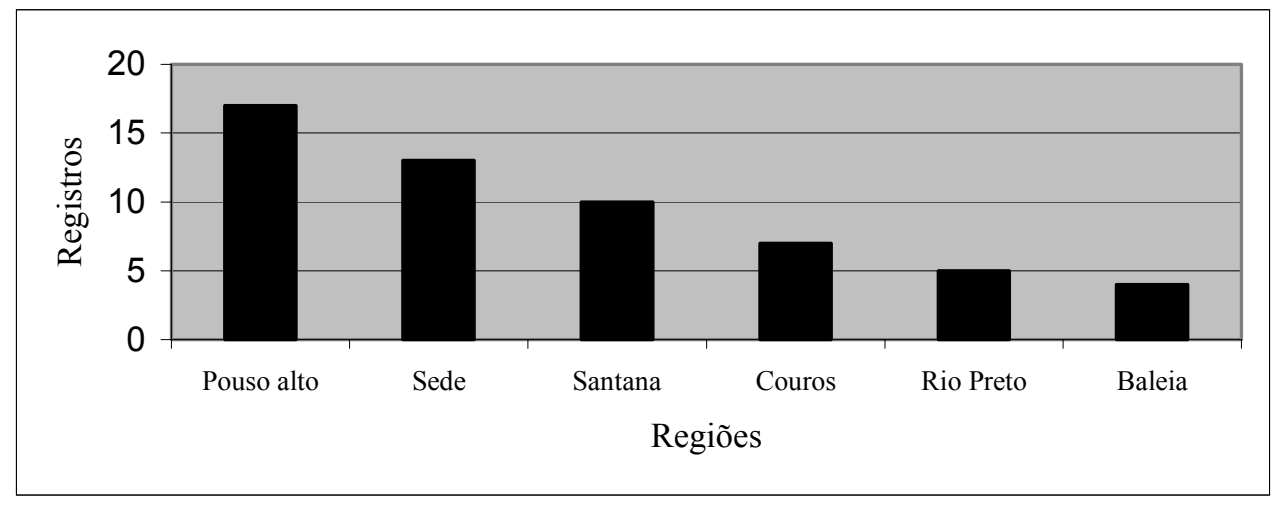

FIGURA 6: Regiões com maior incidência de incêndios no período de 1992 a 2003 no PNCV.

FIGURE 6: Areas with high fires occurrence from 1992 to 2003 in Parque Nacional da Chapada dos Veadeiros, GO.

As regiões com maior ocorrência de incêndios, no período analisado, foram Pouso Alto, área da Sede e Serra de Santana, com 17, 13 e 10 ocorrências respectivamente. Observou-se que, aproximadamente 67\% das ocorrências de incêndios na Unidade, ocorreram nos setores Santana e Pouso Alto, associado à rodovia GO 118. O setor Sede responde por aproximadamente $22 \%$ das ocorrências de incêndios. 


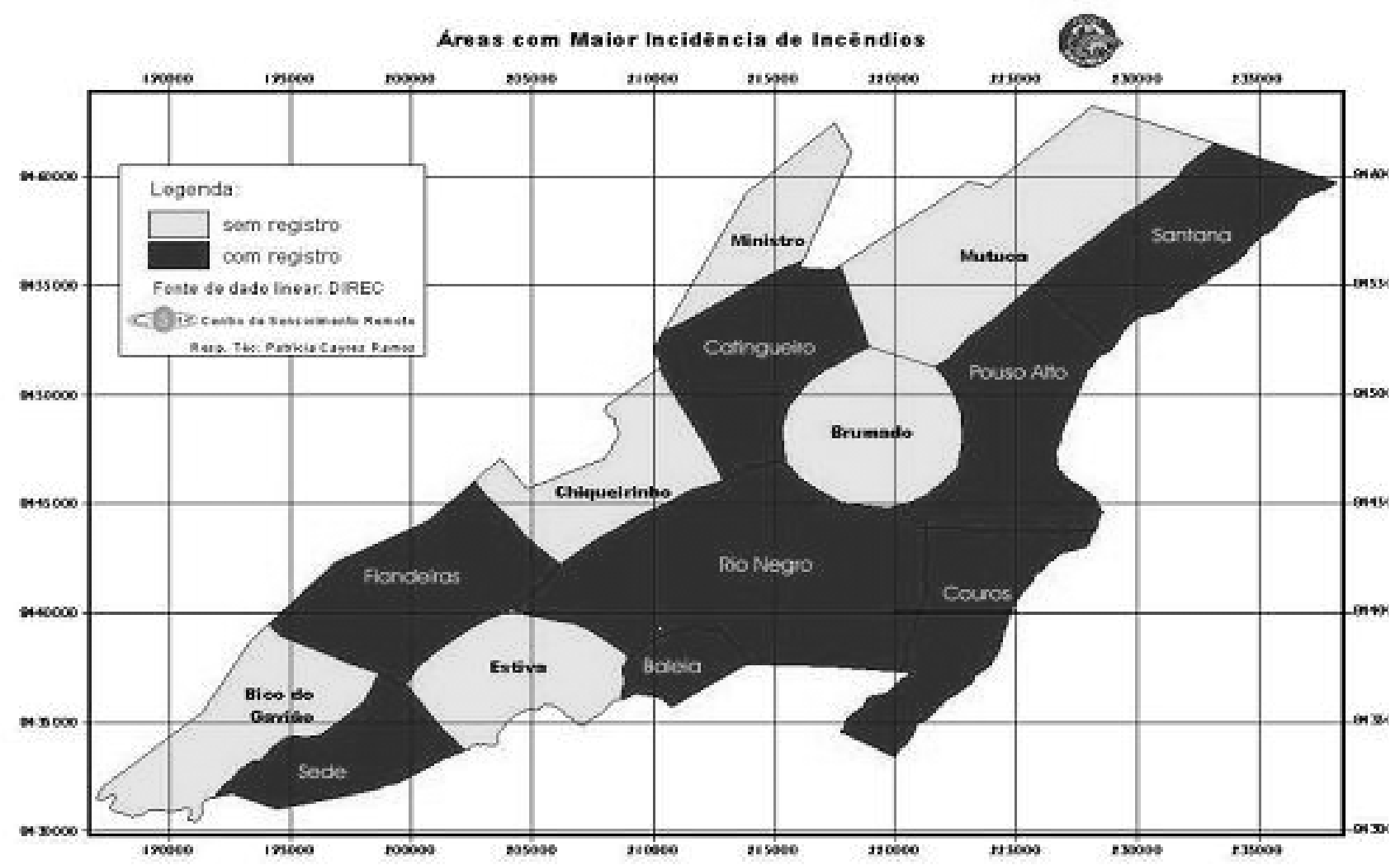

FIGURA 7: Regiões de ocorrência de incêndios no período de 1992-2003 no PNCV.

FIGURE 7: Fires occurrence areas from 1992 to 2003 in Parque Nacional da Chapada dos Veadeiros, GO.

Na Figura 7, as localidades em tonalidade escura constam com pelo menos uma ocorrência de incêndio, enquanto que as áreas em verde não têm registro de ocorrência de incêndio.

\section{Épocas de maior ocorrência de incêndios}

As épocas de maior ocorrência de incêndios florestais no período de 1992 a 2003 no PNCV são grafadas na Figura 8.

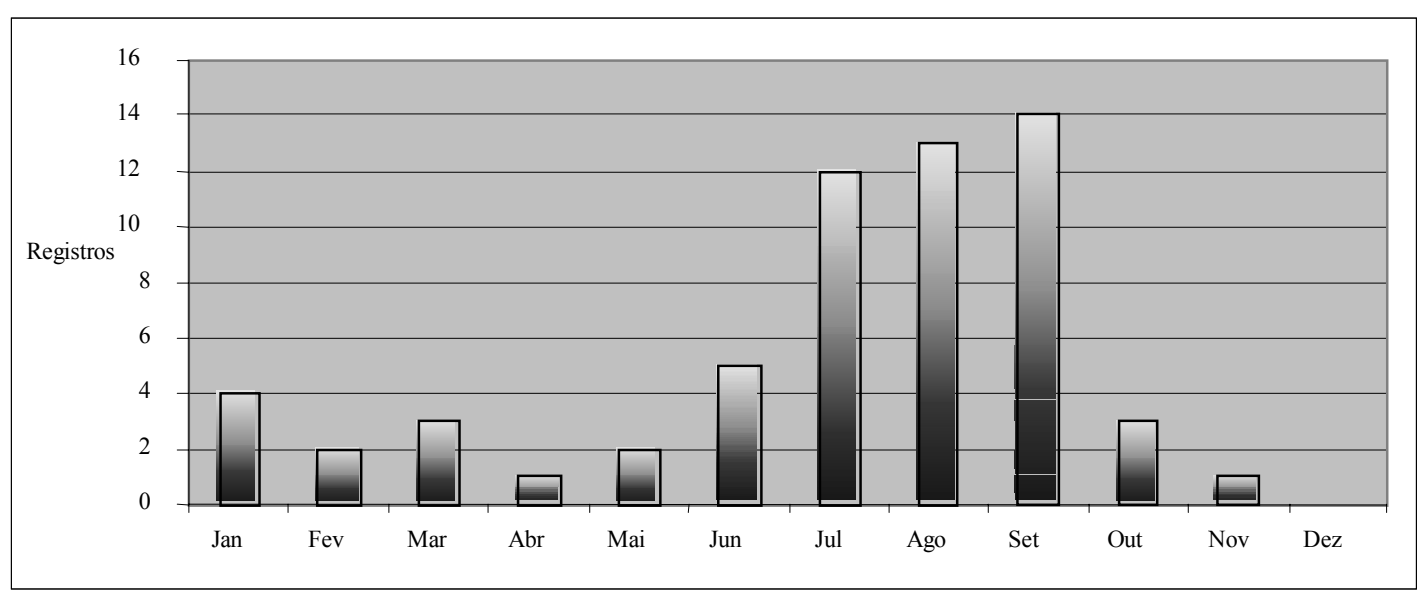

FIGURA 8: Épocas de maior ocorrência de incêndios no período de 1992-2003 no PNCV.

FIGURE 8: Time of biggest fire occurrence from 1992 to 2003 Parque Nacional da Chapada dos Veadeiros, GO. 
Os incêndios no PNCV ocorreram, com maior freqüência, nos meses de julho a setembro (período seco), sendo setembro o mês mais crítico, seguido do mês de agosto e julho respectivamente. Os incêndios nesse período correspondem a $64 \%$ do total das ocorrências de incêndios. Os incêndios provocados por raios ocorrem no período chuvoso e transição seca-chuva, ou seja, entre os meses de setembro e março. Esse padrão de distribuição durante os meses do ano é comum em Unidades de Conservação do Cerrado (Medeiros, 2002; Medeiros e Fiedler, 2004), e reflete a predominância dos incêndios de causa antrópica sobre os incêndios de causa natural, em número de ocorrência, além de atingirem áreas maiores. Assim, os incêndios de causa antrópica constituem uma fonte de distúrbio importante no PNCV, ainda sem estudos locais sobre seus efeitos na biota.

\section{Entrevistas aos brigadistas}

De acordo com as informações referentes às entrevistas, as atividades de prevenção feitas no Parque eram os aceiros e a distribuição de cartazes educativos. Os aceiros são feitos pelos brigadistas do PNCV e também do Parque Nacional de Brasília. A distribuição esporádica de cartazes, nem sempre alcançou o público-alvo no entorno das Unidades de Conservação, considerando as limitações de escolaridade do meio rural brasileiro. A adoção de palestras e visitas programadas às propriedades rurais do entorno, incluindo assistência técnica específica (queima controlada e alternativas ao uso do fogo), podem trazer resultados mais expressivos para a redução da ocorrência dos incêndios (Medeiros e Fiedler, 2004).

A deteç̧ão dos focos era feita pela visualização em pontos mais altos, em primeiro lugar, seguido de informações de satélites e por comunicação com o IBAMA-sede. Da detecção de um foco até a chegada ao local são gastos cerca de 5 min a 4 horas. Esse tempo indica a dificuldade de acesso a alguns locais do Parque e afeta, em muitas ocasiões, a eficiência das ações de combate.

O PNCV contava na época com sete brigadistas que promoviam ações de prevenção e combate aos incêndios. O sistema de comunicação era composto por rádios e telefones celulares. O monitoramento era feito pelo patrulhamento automotivo terrestre e uso de pontos de observação. Para o combate, o PNCV conta com o apoio da brigada, de voluntários e, quando necessário, conta com a ajuda da brigada do Parque Nacional de Brasília. As principais dificuldades encontradas durante o combate eram o deslocamento da brigada e o abastecimento das bombas costais.

\section{Entrevistas à comunidade}

Com a análise de dados referentes às entrevistas aos moradores, $81,8 \%$ moravam há mais de dez anos na região. O conhecimento das áreas do interior do parque foi citado por $90,9 \%$ dos moradores.

A maioria dos moradores do entorno $(58,4 \%)$ conheciam apenas o aceiro como forma de prevenção, $25 \%$ não conheciam nenhuma forma de prevenção aos incêndios e $16,6 \%$ conheciam o uso do próprio fogo para extinguir a vegetação seca nas margens do parque. A maioria dos entrevistados $(54,5 \%)$ afirmou nunca ter recebido orientações de prevenção de incêndios e os outros $45,5 \%$ receberam informações em palestras e reuniões.

Como sugestão para diminuir o fogo no parque e adjacências, $25,1 \%$ dos moradores, salientaram a necessidade de treinamento em técnicas de substituição do uso do fogo e queimada controlada, 16,7\% consideraram a necessidade de conscientização dos turistas e da comunidade. A construção de aceiros, o aumento da fiscalização, a indenização aos ex-proprietários de terra do parque, o manejo de fogo e o trabalho de prevenção na comunidade representaram $8,3 \%$ cada um. Importante observar que a maioria dos moradores considera que não existe um trabalho de prevenção adequado nas comunidades urbana e rural.

\section{CONCLUSÕES}

Os incêndios no PNCV ocorreram com freqüência elevada, de causa criminosa ou desconhecida. A grande quantidade de incêndios de causa desconhecida pode ser em conseqüência da falta de pontos da observação e à ausência de perícias após os incêndios.

Os incêndios eram provenientes, em sua maioria, das fazendas do entorno da Unidade e nas proximidades da Rodovia GO-118 sendo, provavelmente, originados de queima de pastagens. Os incêndios atingiam extensas áreas, seguindo um padrão comum a outras Unidades de Conservação do Cerrado. 
A época de maior ocorrência de incêndios foi durante a estação seca. Os incêndios ocorridos fora desse período impactaram áreas menores e também eram mais fáceis de ser combatidos por causa da maior umidade local.

Formas alternativas de prevenção como palestras e assistência técnica ainda não foram utilizadas de forma abrangente. O PNCV conta com poucos brigadistas que realizam as funções de prevenção e combate aos incêndios.

A comunidade do entorno considerou que falta estímulo à difusão de técnicas de substituição do uso do fogo na região e campanha educativa aos turistas e à própria comunidade. A maioria dos entrevistados afirmou que nunca tiveram orientações de prevenção de incêndios florestais.

\section{REFERÊNCIAS BIBLIOGRAFICAS}

IBAMA. Plano Emergencial do Parque Nacional da Chapada dos Veadeiros-GO. Brasília : IBAMA,1995. 87p. (Relatório Técnico)

MATOS, E. F. Prevenção e combate aos incêndios florestais em unidades de conservação. In: FÓRUM DE PREVENÇÃO E COMBATE AOS INCÊNDIOS FLORESTAIS DO DF, 6 2004, Brasília. Anais... Brasília: SEMARH, 2004. p. 19-30.

MEDEIROS, M. B. Manejo de fogo em unidades de conservação do cerrado. Boletim do Herbário Ezechias Paulo Heringer, Brasília, v. 10, n. 1, p. 76-89, 2002.

MEDEIROS, M. B.; FIEDLER, N. C. Incêndios florestais no Parque Nacional da Serra da Canastra: desafios para a conservação da biodiversidade. Ciência Florestal, Santa Maria, v. 14, n. 2, p. 157-168, 2004.

NEPSTAD, D.C.; MOREIRA, A.G.; ALENCAR, A. A. A floresta em chamas: origens, impactos e prevenção de fogo na Amazônia. Brasília : Ministério do Meio Ambiente. Programa Piloto para a Proteção das Florestas Tropicais no Brasil, 1999. 172p.

SISTEMA NACIONAL DE PREVENÇÃO E COMBATE AOS INCÊNDIOS FLORESTAIS-PREVFOGO. Programa de Manejo de Fogo do Parque Nacional da Chapada dos Veadeiros. Brasília : IBAMA, 2004. 135 p. (Relatório Técnico do IBAMA)

RAMOS-NETO, M. B. O Parque Nacional das Emas (GO) e o fogo: implicações para a conservação biológica. 2000. 187f. Tese (Doutorado) - Universidade de São Paulo, São Paulo, 2000.

SILVA, E. P. R. Efeito do regime de queima na taxa de mortalidade e estrutura de vegetação lenhosa de campo sujo de cerrado. 1999. 142f. Dissertação (Mestrado em Ecologia) - Universidade de Brasília, Brasília, 1999.

SOARES, R. V. Prevenção e controle de incêndios florestais. Curitiba : FUPEF, 1985. 72p.

VICENTINI, K. R. C. F. História do fogo no cerrado: uma análise palinológica. 1999. 235f. Tese (Doutorado em Ecologia) - Universidade de Brasília, Brasília, 1999. 